ESCRITAS Vol. 9 n. 2 (2017) ISSN 2238-7188 p. 56-70

\title{
RELAÇÕES COM O SABER: NARRATIVAS DE ALUNOS DA EDUCAÇÃO BÁSICA SOBRE ENSINO DE HISTÓRIA
}

\section{RELATIONHIPS WITH KNOWLEDGE: NARRATIVES OF STUDENTS FROM BASIC EDUCATION ABOUT HISTORY TEACHING}

Tiese Teixeira $\mathrm{Jr}^{1}$

\begin{abstract}
RESUMO: O objetivo deste artigo é analisar as narrativas de alunos do ensino médio acerca do ensino de história, em contextos de leitura e de escrita. Entende-se que no processo de ensino da história escolar, o uso da linguagem na forma falada ou escrita, pode ser um a "estratégia" facilitadora do processo de ensino e aprendizagem, numa perspectiva de construção de significados na relação com saber histórico e também, um instrumento de fortalecimento das identidades e da cidadania no cotidiano escolar. A rede teórica dialoga com os trabalhos de Adorno (2003), Certeau (2016), Ross (2016) e Charlot (2001). No aspecto metodológico, a análise se concentra num corpus retirado de narrativas escritas, que tratam do ensino de história, feitas pelos alunos do primeiro ano do ensino médio, da escola Estadual Anunciada Chaves, do município de Goianésia do Pará, estado do Pará.
\end{abstract}

PALAVRAS-CHAVE: Ensino de História; Leitura; Escrita.

ABSTRACT: The objective of this article is to analyze the narratives of students from high school about history teaching in reading and writing contexts. It is understood that in the process of teaching scholar history, the use of oral and written language form could be a facilitative strategy in the learning and teaching process in a perspective of construction of meanings taking into account the historical knowledge and also, it is an instrument to strengthen identities and citizenship in everyday school. The theoretical aspect discusses the works of Adorno (2003), Certeau (2016), Ross (2016) and Charlot (2001). In the methodological aspect, the analysis focuses on a corpus retired from written narratives about history teaching made by students from the first year of high school; at the basic school Anunciada Chaves of Goianesia do Pará municipality, Pará State.

KEYWORDS: History Teaching; Reading; Writing.

\section{INTRODUÇÃO}

O objeto de estudo deste artigo são trechos de narrativas de alunos do ensino médio, da escola Estadual de Ensino Médio, Anunciada Chaves, de Goianésia do Pará, Pa. O ponto de partida é analisar a relação com o saber histórico no ensino básico, através dos significados

\footnotetext{
${ }^{1}$ Professor da rede pública de ensino do estado do Pará. Doutorando em Ciência Socioambiental, pelo Núcleo de Altos Estudos Amazônicos, NAEA, da Universidade Federal do Pará. Bolsista CAPES. Membro dos Grupos de Pesquisa: GEPEMSSP e Recursos Naturais e Desenvolvimento Regional, da Universidade Federal do Sul e Sudeste do Pará, UNIFESSPA. Email: tiesejr@gmail.com
} 
atribuídos pelos alunos às aulas de história mediadas por leitura e escrita. O objetivo geral é compreender, como uma proposta metodológica de ensino de história baseada na Língua Portuguesa é interpretada nas narrativas dos estudantes envolvidos no processo. Para chegar ao objetivo proposto será feito uso de um corpus retirado de uma avaliação escrita feita pelos alunos, de duas turmas do primeiro ano do ensino médio da referida escola.

No corpus escolhido, os alunos avaliam as aulas de história, com foco na leitura e na escrita e apontam os significados construídos a partir desta proposta de ensino.

\section{TECENDO UMA REDE TEÓRICA}

Falar em ensino e aprendizagem na educação básica é falar em metodologias, estratégias, recursos, criatividades, novidades...e acima de tudo desafios. O ensino da história escolar está neste universo. As aproximações teóricas que se seguem buscarão no vocabulário conceitual de Adorno (2003), Certeau (2015), Charlot (2001) e Ross (2016), os suportes para ajudar na aproximação e no entendimento do objeto em estudo.

Adorno (2003) ajuda a pensar processos de educação, em termos mundiais e chama a atenção para o fato de que os planejamentos educativos são pensados e conduzidos a partir, primeiramente de metas quantitativas. Os números aparecem como as metas a serem alcançadas pelas políticas de estado. É preciso, diz ele, que elementos de ordem qualitativa sejam colocados na agenda, sem excluir os quantitativos, afinal as necessidades materiais fazem parte do fazer educativo, mas não só ela.

Outros termos vindo do seu vocabulário conceitual que ajudam a pensar, a prática docente no ensino de história, em especial, são a "indústria cultural" e a "modelagem de pessoas". A indústria cultural, de forma homogênea cria ou reduz a produção da cultural à mercadoria, para que a massa consuma. Assim, a indústria da moda e do corpo magro, tido como o perfeito, por exemplo, está ai para exemplificar isso. Essa ideia se expande para a prática da dita educação formal colocada em curso nas escolas, onde a transmissão do conhecimento dá o tom do modelo vigente.

Ao tratar da educação, Adorno 2003, diz:

Gostaria de apresentar a minha concepção inicial de educação. Evidentemente não assim chamada de modelagem de pessoas, porque não temos o direito de modelar pessoas a partir do seu exterior; mas também não a mera transmissão de 
conhecimentos cuja característica de coisa morta já foi mais do que destacada, mas a produção de uma consciência verdadeira. (p.141).

O termo "modelagem de pessoas" em processos de educação é muito presente em nossos contextos sociais. A partir do discurso da ciência buscam-se modelos ideais de pessoas. Ao transpor isso para a educação existe uma prática que trata os alunos como se fossem todos iguais. No campo da educação, a indústria cultural opera, também, através dos livros didáticos que trazem modelos de como ser professor e a formula para ministrar suas aulas. Nesse universo há pouco espaço para criar o novo. É mais fácil copiar o modelo pronto. Somos formados para temer a criatividade e preferir seguir o modelo que já existe. (Adorno, 2003).

O fazer docente é composto de pequenos sucessos, e neste sentido as ações de educação precisam valorizar conhecimentos vindos de outras áreas, que podem ajudar na construção de "estratégias", para superar os desafios impostos no cotidiano escolar. Entre estes desafios, as ampliações das capacidades de leitura e de escrita nas aulas de história figuram como elementos-chave. Aqui, o conceito de "estratégias" emprestado de Certeau (2016) é um facilitador para compreender esse universo, pois, colocar em curso aulas de história mediadas por ações de leitura e de escrita é uma estratégia para conduzir o ensino e a aprendizagem da história escolar no ensino básico.

Uma das questões colocadas para o ensino da história é a de como despertar o interesse do aluno por esta área do conhecimento. Neste sentido Charlot (2001) ajuda a pensar a questão ao chamar a atenção para a relação dos jovens com o saber. Os professores se deparam com a realidade em que a relação com o saber geral, com este ou aquele saber é marcada pelo "desinteresse" do aluno. Diz ele:

Isso significa que não se pode definir o saber, o aprender, sem definir ao mesmo tempo uma certa relação com o saber, com o aprender. Significa ainda que não se pode ter acesso a um saber ou mais genericamente aprender, se ao mesmo tempo não entrar nas relações que supõe esse saber, este aprender. (Charlot, 2001, p. 17)

Numa perspectiva sociológica, por exemplo, o fracasso escolar e a repetência figuram como "fantasmas" na vida escolar. Charlot (2001) lembra que a reprovação acontece com mais força entre os alunos oriundos das camadas mais pobres da sociedade. Nesse universo, a relação dos alunos com o conhecimento não é a mesma nas diferentes classes sociais. 
Entender como se constroem essas relações no ensino de história, nos dias recentes é importante para os processos educativos em curso.

Acredita-se, também, que, no processo de fortalecimento da relação com o saber a linguagem seja um instrumento importante. A língua ajuda a vencer dificuldades de participação social, a palavra, escrita ou falada, pode conferir identidade e tornar-se um instrumento de ação política e educacional. De acordo com Ross (2016), pelo uso da palavra a pessoa pode perceber suas forças e fragilidades e "superar os desafios do seu grupo social" (Ross, 2016, p.48). A sala de aula é um espaço social onde podemos marcar a nossa história e fortalecer a individualidade. Dito de outra forma:

Pela palavra, nós aprendemos a escutar, dar atenção ao outro, perceber nossas diferenças. Escutar é uma maneira de dar afeto, permitir que o outro reelabore sua compreensão. Escutar é uma maneira de outro atribuir flexibilidade em nosso ponto de vista. Escutar é autorizar o outro a enriquecer e modificar nossa experiência. (Ross, 2016, p.49).

Assim, o ato de "escutar" pode ser vinculado a uma "estratégia" de ensino de história, uma vez que nas aulas, a leitura dos textos produzidos pelos alunos, por exemplo, seja utilizada de forma permanente no período letivo em um contexto que objetive o fortalecimento dos laços sociais e das identidades, tendo a linguagem como um caminho para o exercício da cidadania na história escolar.

\section{O QUE SE DIZ DA RELAÇÃO COM O SABER HISTÓRICO NO ENSINO BÁSICO?}

Parte dos debates sobre o ensino de história tem chamado atenção para um problema freqüente enfrentado pelos professores da disciplina, o fato de terem que ensinar história para 
alunos que não dominam de forma satisfatória a leitura e a escrita. Alguns estudos mostram que os professores olham isso com "estranhamento e queixa", junto a isso, a falta de livros e as representações criadas pelos professores, sobre os alunos, como sendo mais ou menos letrados, têm direcionado tanto as escolhas didáticas quanto o grau de problematização da história ensinada na escola pública. (Rocha, 2010).

Bento (2012) ao tratar do saber histórico e sua relação com o ensino de história, argumenta que este tem uma relevância social e precisa preparar o aluno para ler e viver a história de forma crítica. Aponta que o trabalho do professor de história vai além da sala de aula e os desafios colocados no cotidiano desses profissionais, passa pela de falta de recursos materiais, e isso atrapalha o processo de ensino. É preciso que o conhecimento histórico prepare o indivíduo para a vida em uma sociedade cada vez mais carente de educação. Sobre as pesquisas que tratam do ensino de história, ele diz:

Os estudos contemporâneos que envolvem o Ensino de História, diante de suas limitações possuem características a tempo estudadas, que nos direcionam a novas abordagens, trazendo novos conceitos, e assim percebemos a responsabilidade de desenvolver mudanças no cotidiano escolar. Visto que a educação brasileira clama por transformações, baseadas, sobretudo no aprendizado que devemos buscar a todo instante de nós mesmos enquanto sociedade e também como indivíduos. (Bento, 2012, p.10).

Ribeiro (2009) em trabalho que aborda o ensino de história da educação básica foca a análise na relação do ensino da história com os conhecimentos vindos da didática. Destaca que a diversidade nas formas de ensinar precisa ser considerada e que a separação existente entre os conhecimentos vindos da ciência histórica e os vindos da didática, em muitos casos ainda se apresentam separados e isso é um desafio que precisa ser superado.

Sobre as possibilidades para se trabalhar o conhecimento histórico em sala de aula do ensino básico, e a importância dedicada ao "método" de ensino, ela diz:

\footnotetext{
Usando uma diversidade de técnicas como: a pintura, o filme, o documentário, a música, o teatro, a poesia, o romance, os para-didáticos, o uso de mapas, as palestras e outros; temos ainda as práticas em sala que podem dar mais dinamismo às aulas, como trabalhos em grupo e de campo, além de uma diversidade da didática que permita ao professor mostrar o quanto o conteúdo histórico é rico e tem importância na vida de cada aluno. (Ribeiro, 2009, p.09).
}

Os trabalhos trazidos aqui, por um lado, a formação para a cidadania, a construção de uma consciência crítica, a preparação para a vida fazem parte das linhas norteadoras das reflexões que tratam do ensino da história, por outro lado, os desafios, materiais e simbólicos colocados ao fazer docente na escola básica também compõem essas análises. 
No estado do Pará, por exemplo, os alunos chegam ao último ano do ensino médio com problemas para compreender os conhecimentos históricos próprios desta etapa escolar. Fazer-se compreender lendo, escrevendo ou interpretando é uma tarefa delicada vivida por professores e alunos. Na maioria das escolas da região sudeste do Pará, por exemplo, o único livro disponível é o livro didático. Nem sempre o livro enviado pelo Ministério da Educação (MEC) é o mesmo que foi escolhido pelos professores da escola; O tempo das aulas no turno da noite é muito menor que o tempo do dia; A prática de ensino disciplinar ainda é hegemônica. O professor de história pouco trabalha leitura, e a escrita trata de cópias de parte do livro, em trabalhos que objetivam dar uma tarefa ao aluno para fechar uma nota bimestral. Realidade presente em outras escolas públicas do país. (Rocha, 2010).

Uma prática de ensino de história comum, nas escolas de ensino médio da Amazônia Paraense é o uso do seminário. Nele, o professor divide a turma em várias equipes e cada uma recebe um capítulo do livro. Os alunos apresentam um "resumo" do tema trabalhado por sua equipe e fazem uma comunicação oral, em que leem partes do assunto. Ao final, um dos capítulos é escolhido para a prova bimestral, que é de múltipla escola, e se baseia nas questões propostas no livro didático, já que muito professores trabalham nos turnos da manha, tarde e noite, na rede municipal e estadual, fato que limita o tempo para o planejamento escolar.

Entende-se que, por exemplo, a longa jornada de trabalho dos professores e o número excessivo de turmas e alunos são fatores que prejudicam diretamente a qualidade de suas aulas, pois, no caso da escrita na aula de história é preciso que haja um tempo para ler os textos, corrigi-los e orientar a reescrita, já que se trata de alunos "não letrados". (Rocha, 2010).

\section{E POR FALAR EM HISTÓRIA REGIONAL}

Este trabalho busca pensar uma relação com o saber histórico escolar, que possa ajudar dentro do quadro mostrado acima, e neste sentido, fazer um recorte para o ensino da história regional é algo que se considera pertinente. Assim, a história da Amazônia, enquanto 
um saber historicamente construído precisa ser pensado em sua particularidade. Por exemplo, em questões como: Qual a relação com o saber histórico regional está sendo construída na escola básica amazônica? Quais matrizes sociais e culturais estão compondo esses saberes? Como a diversidade humana interage nas aulas de história? Essas questões são aqui levantadas, para ajudar a provocar o tema da construção das relações com o saber histórico; que o ensino da história regional possui desafios próprios e que a busca por estabelecer relações com o saber passa por pensar o global, mas também, o local.

Para ajudar a compor um pequeno quadro sociohistórico da região, e, também, para situar o leitor no universo da pesquisa em tela, é válido citar que a Amazônia do sudeste paraense, por diferentes caminhos foi constituída por seus povos tradicionais e por imigrantes: ricos e pobres, homens e mulheres, em uma dinâmica socioambiental fortemente assentada na expansão capitalista. "A formação da sociedade na Amazônia tem estado intimamente ligada à colonização e à economia" (Batista, 2006, p.68). Essa afirmativa ganha um sentido forte quando se fala da Amazônia do sul e sudeste do Estado do Pará. Sua constituição histórica tem sido marcada por intensas lutas da sociedade pela conquistas, manutenção e exploração dos recursos naturais. Sendo também verdade que nela, o homem tem influído de maneira negativa sobre o meio natural. (Batista, 2006).

A ocupação dita planejada e sistemática da região amazônica como um todo, a partir dos anos de 1960-1970, evidenciou-se no sul e sudeste paraense, após a construção da Rodovia Belém-Brasília e da Transamazônica. Nesse Período, o estado brasileiro transformou a antiga Superintendência do Plano de Valorização Econômica da Amazônia (SPVEA), em Superintendência de Desenvolvimento da Amazônia, (SUDAM), criou o Banco da Amazônia (BASA) e a Zona Franca de Manaus. Tudo para estimular o crescimento econômico. (Oliveira, 2007).

Nos anos de 1980, grandes investimentos foram direcionados para o polo Mínerometalurgico de Carajás, parte dele sendo implantado no sudeste do Pará. Essa empreitada exigiu o aumento do eixo rodoviário na região, e desenvolveu outros polos econômicos voltados à extração da madeira e exploração pecuária. Assim, os recursos naturais da região e o planejamento estatal provocaram uma atração espontânea de imigrantes de diferentes partes do país. Uma parte deles dispondo de capital, outra parte buscando oportunidades de trabalho. 
Historicamente a dinâmica da economia mundial mostrou/a seus reflexos nesta Amazônia em particular, uma vez que a demanda externa por commodities tem dado a tônica da economia dessa região representada, por exemplo, na intensa exploração mineral, que tem colocado em risco a integridade do ecossistema. Outro ponto a ser considerado são os fortes conflitos no campo pela posse da terra, uma vez que a expansão do agronegócio tem expulsado migrantes, colonos e assentados de suas terras. Conflitos agrários que por vezes, também, migraram para a região. Outro dilema socioambiental, que não é registrado apenas na região sul e sudeste do Pará é a prática do trabalho escravo, uma vez que "os registros sobre trabalho escravo acontecem nos estados da Amazônia, o que indica outras faces da ilegalidade na região"

Com relação à história das tragédias humanas regionais, no âmbito das relações socioambientais e dos trabalhadores pobres, que migraram para a região amazônica e em especial, rumo ao estado do Pará, muitos em boa medida movidos pela busca da sobrevivência, registrou de forma amarga aquilo que ficou conhecido mundialmente como o “O Massacre de Eldorado dos Carajás”, quando no dia 17 de abril de 1996, 17 trabalhadores sem-terra foram brutalmente assassinados, na Rodovia PA-150, local conhecido como "curva do S", esse episódio compõe" o quadro alarmante da violência agrária no Pará, conseqüência do processo histórico do desenvolvimento econômico da região Norte, com fatores sociais e políticos, fortemente atravessado por uma exploração mineral e agropecuária nas regiões sul e sudeste do estado. Dos 19 trabalhadores mortos, a maioria eram oriundos dos estados do Maranhão, Piauí e Pernambuco. (Teixeira Júnior, 2017).

Os estudos indicam que no sul e sudeste do Pará, a intervenção estatal tem privilegiado as atividades econômicas ligadas à pecuária extensiva, a exploração da madeira e do minério como o mote do desenvolvimento regional. Neste cenário houve a marginalização dos povos indígenas, posseiros, pescadores, agricultores familiares e demais trabalhadores migrantes. Os que levantam a voz, contra esse desenvolvimento da "pata do boi", como os movimentos sociais do campo, são chamados de baderneiros e invasores, que querem impedir o "progresso" da Amazônia.

Esses movimentos sociais enfrentam historicamente a violência imposta pelos grandes proprietários rurais. Existe um estado de tensão permanente, e nos casos de assassinatos de trabalhadores rurais, poucos casos são levados a júri, somente aqueles de grande repercussão. Os que ameaçam e matam estão cobertos pelo manto da impunidade. Os assassinatos de João 
Canuto de Olivera, Expedito Ribeiro de Souza e Dorothy Stang, fazem parte desse quadro. (CPT, 2012).

No século XX, no ocidente, definiram-se os parâmetros daquilo que se convencionou chamar de Agricultura Moderna, quando as mudanças tecnológicas, nascida na Revolução Industrial Inglesa, do século XVIII, industrializaram de forma acentuada a agricultura no mundo ocidental, diminuindo sua dependência dos processos e recursos naturais. Passo a passo, as frações da produção foram sendo dominadas pela indústria. Esse novo modelo foi levado ao topo a partir da década de 1960, sendo chamado de "Revolução Verde". Se por um lado houve o aumento da produção, por outro a agressão ao meio natural atingiu patamares nunca antes visto. Na busca pela melhoria das condições de vida, a sociedade moderna ocidental passou a tratar o meio natural como um obstáculo a ser ultrapassado. A relação estabelecida com a natureza passou a ser de antagonismo.

Esse processo de modernização expressou claramente as bases do pensamento Cartesiano, de separar a sociedade da natureza, que deveria ser manipulada pelo homem e existir apenas para satisfazer suas necessidades. Eram os humanos contra a natureza. Essa lógica de apropriação moderna desembarcou na Amazônia brasileira desde os tempos coloniais, mas, foi a partir do governo militar, 1964/1985, e de suas políticas de desenvolvimento, que ela ganhou fôlego e se fortaleceu na região amazônica. $\mathrm{Na}$ visão das elites do país, a região amazônica aparecia como um local onde estava estocado uma infinidade de recursos naturais, que permitiriam ao capital refazer seu ciclo de acumulação, o Estado tomou a frente do projeto de desenvolvimento apresentado ao país, como a solução para os problemas econômicos e sociais da época.

Esse ideal de progresso via um crescimento linear e sem fim, que buscava na incorporação de terras e de recursos naturais infindáveis o seu trunfo. Como pano de fundo, o ideal moderno dizia que para o projeto ter sucesso era preciso transformar a natureza selvagem, em dominada, e fazê-la gerar lucros. Assim, a incorporação da Amazônia ao resto do Brasil, passaria antes de tudo, pela transformação do seu espaço natural, através do trabalho humano. Com essa visão, o espaço amazônico foi ocupado.

Nesse processo de redistribuição territorial, proposto pelo governo militar, a agricultura colocada em prática, desde o inicio estava vinculada a um grupo, o das empresas capitalistas. Nesse modelo ganhava destaque a expansão do mercado da indústria de tratores, adubos químicos, sementes, elementos chave, na agricultura moderna proposta pelo Estado. A 
lógica de exploração era capitalista. As atividades de pecuária extensiva logo receberam ajuda de custo do governo, para facilitar seus empreendimentos. Esse projeto buscava substituir florestas por pastagens, e acabar com o "isolamento e o vazio humano", da região como afirmava o discurso hegemônico do capital, para este, a terra só tinha valor se fosse transformada em pasto.

Houve um bloqueio ao desenvolvimento de uma agricultura familiar, que ia de encontro a esses princípios. Mesmo assim, ela não deixou de se desenvolver a tornar-se um importante setor da produção agrícola regional. O intenso movimento migratória para região é explicado em boa medida, pelos programas oficiais de colonização deslocando camponeses e trabalhadores, especialmente do Nordeste e centro-sul, motivados pelo sonho de conseguir terra para plantar, mas também, encontrar trabalho nas obras de infraestrutura, atividades de exploração de madeira e minério.

O desconhecido meio natural amazônico impôs dificuldades a esses migrantes, e a visão de que a natureza era apenas uma reserva de bens naturais, levo-os a estabelecer uma relação de exploração, também agressiva ao meio natural. Porém, a exploração dos recursos naturais era feita para a subsistência familiar. Assim, os diferentes agentes sociais impuseram diferentes formas de se relacionar com a natureza regional. No caso do Sudeste do Pará, região em que grandes projetos foram implantados, a produção de energia elétrica, também com a finalidade de exploração mineral transformou Marabá e região num polo de referência, na disputa entre diferentes segmentos sociais pela posse e uso da terra. Nesse espaço, a concentração fundiária tem se mantido nas mãos do grande capital.

Mesmo com os esforços do governo militar, em colocar em prática a agricultura moderna na região amazônica, os avanços foram lentos. Na região sul e sudeste do Pará, a "Revolução Verde" não se desenvolveu como em outras partes do país. A utilização dos insumos e máquinas na produção não alcançou os objetivos esperados, mesmo nos grandes empreendimentos agropecuários. Isso também ocorreu com os ganhos na produção, que ficaram bem distantes das metas do governo. Com tudo é fato que a lógica industrial da agricultura moderna entrou, e definiu os padrões da produção agropecuária na região, essa constatação pode ser observada a olho nu, em nossos dias, através da proliferação de adubos químicos, agrotóxicos, máquinas e áreas de cultivos de monoculturas, em especial, as de eucalipto. (Oliveira, 2007). 
É neste universo, que se encontra o município de Goianésia do Pará, que foi fundado em 1991 e está localizado no sudeste do estado do Pará, na região de integração do Lago de Tucuruí. É limítrofe aos municípios de Ipixuna do Pará, Breu Branco, Dom Eliseu, Rondon do Pará, Jacundá, Paragominas e Novo Repartimento. Sua área abrange 7.003,1 quilômetros quadrados, que abriga 30.436 habitantes, dos quais $69 \%$ estão na área urbana e 31\%, na área rural (Imazon, 2012).

A cidade possui apenas uma escola de ensino médio. A formação social da população comporta gente de várias partes do país, em especial, Minas Gerais, Maranhão e Pará. Há uma diversidade social expressiva, que se reflete de forma intensa, por exemplo, na linguagem, e nesse encontro com diferentes referências de cultura, a educação escolar ocupa lugar central, como um maestro, a reger uma orquestra.

\section{DA RELAÇÃO COM A HISTÓRIA ENSINADA: RELATOS DE ESTUDANTES.}

Pode-se dizer que o ensino público brasileiro ainda não garante aos seus alunos as condições necessárias e suficientes para o desenvolvimento de uma relação pessoal significativa com os saberes, tão relevante para o êxito da aprendizagem. (CHARLOT, 2001, p.33).

O corpus analisado a seguir é resultado de uma avaliação escrita feita pelos alunos do ensino médio, da escola Estadual Anunciada Chaves, do Município paraense de Goianésia do Pará. O objetivo proposta era que os alunos avaliassem as aulas de história do ano de 2016, que foram norteadas por sessões de leitura pública e escrita/reescrita de textos sobre temas como: história antiga, história medieval e história moderna. Os trechos abaixo buscam marcar, aproximações com as reflexões que tratam da relação com o saber, dos processos de emancipação e das estratégias possíveis, para a construção de significados num contexto de ensino de história. Nos enunciados serão buscados relações de afeto com a disciplina e em que contribuíram para o avanço do conhecimento construído pelos alunos. Será mantida a escrita original dos alunos, para o registro, de como se expressam na língua materna.

(A1) [..... a leitura na sala de aula foi bom pois ajudou alguns alunos perderem a vergonha de lê. A parte escrita também foi ótima, pois, alguns alunos como eu melhoraram a escrita. A matéria de história pra mim é a melhor matéria.

(A2) [..... em suas atividades o professor nos ensina e avalia a nossa escrita, leitura e o desenvolvimento sobre o assunto estudado fazendo com que possamos aprender não só a disciplina de história, como de português também. 
(A3) $[\ldots . .$.$] a aula de história é muito interessante por ter leitura, escritas, silencio,$ participações. Ler em público não é fácil, aprendi como perder o medo, antes eu lia muito rápido e com muito nervoso. Ler em público é um desafio, achei positivo.

(A4)[.... antes da aula de história eu não lia, só lia no face. Agora estou no quinto livro, to lendo o Diário de Anne Frank. No começo achava muito chato ter que ler na sala de aula agora sinto falta. (...) eu aprendi a gostar da matéria de história e ainda aprendi a fazer redação sei que a redação é importante também.

(A5) [..... mesmo sendo uma matéria complexa as leituras e os textos produzidos ajuda os alunos a melhorar seu rendimento escolar e seu interesse na matéria aumenta, não só nas suas aulas mas também nas outras(...) a escrita se torna melhor a cada dia.

(A6) [.....] sobre as leituras eu coloco como ponto positivo, pois, tem muitas pessoas como eu que não conseguem se expressar em público, então isso é muito bom. Outro ponto é a escrita, muita produção de texto essa prática com certeza irá nos ajudar. Aprendia história na aula sem perceber. $\mathrm{O}$ professor nos ensinou como fazer um texto.

Os relatos tratam da leitura e da escrita na aula de história, estas são utilizadas como uma estratégia de ensino de história, e tem entre seus desdobramentos a criação de uma relação de afeto com a disciplina. No trecho 1 (A1) "A parte escrita também foi ótima" "A matéria de história pra mim é a melhor matéria". A aula é aqui descrita nas duas dimensões, na primeira a qualificação como sendo algo que se gosta, e no segundo caso, a relação de afeto, que segundo Charlot (2001) é um componente importante no processo de relação com o saber, no caso o saber histórico.

No trecho 2 (A2) o aprendizado da Língua Portuguesa aparece como algo a mais, um bônus na aula, há uma voz nesse discurso que diz que ele não sabia Português antes da aula de História, isso representa um divisor no processo de ensino se pensarmos que não é possível que se aprenda nenhuma área do conhecimento sem a língua materna. Isso nos remete ao pensamento de Adorno (2003), que chama a atenção para a deficiência da educação no que tange as linguagens, diz o estudioso:

Seria preciso estudar o que as crianças hoje em dia não conseguem mais aprender: o indescritível emprobrecimento do repertório de imagens, o empobrecimento da linguagem e de toda a expressão. (p.146)

O trecho 3 (A3) traz a leitura pública como fio condutor do processo de ensino. $\mathrm{O}$ reconhecimento de que a leitura pública é um desafio é o que a faz necessária como lembra Ross (2016) dar a palavra é dar a oportunidade de se contar uma história. Quem lê conta uma história, fala de um lugar. Quem não lê, também, conta uma história de silenciamento. 
Os trechos 4 (A4), e (A5) apontam os avanços trazidos pela aula de história, e podem ser aproximados do que Charlot (2001) chama de relação significativa com o saber. Uma vez que os significados afetivos e os avanços são apontados. "antes da aula de história eu não lia, só lia no face. Agora estou no quinto livro, tô lendo o Diário de Anne Frank."

"Aprendia história na aula sem perceber. O professor nos ensinou como fazer um texto". Este trecho (A6) justifica o uso da língua materna como estratégia de ensino de história, pois, o "não perceber" não é lido como desimportante, mas como algo "leve" a história escolar fui por outros caminhos na sala de aula, e "o complexo" da disciplina, apontado em um dos trechos acima, pode ser apreendido.

Essa é uma das intenções do uso da leitura e da escrita no ensino de história escolar. Outra voz, no mesmo enunciado fala que na aula de história se aprendeu a fazer um texto, isso aponta, dentre outras perspectivas, uma relação mal construída com a disciplina de língua Portuguesa, por um lado, a aula de história aparece como sendo um lugar do reencontro com a língua materna e seus desdobramentos.

\section{ALGUMAS CONSIDERAÇÕES}

Pensar um espaço docente que não seja, o qual você atua, é um exercício bem exigente. Quando se fala em ensino, projetamos nas reflexões o nosso lugar de fala, e isso por si, já configura um desafio para se pensar docência no ensino básico. Cada lugar tem suas referências. Uma turma nunca será igual à outra, mesmo que esta seja a turma ao lado, no mesmo corredor, da mesma escola. As propostas para o ensino público parecem que ainda caminham no sentido de pensar formações escolares iguais, para professores e alunos diferentes. O que se faz aqui poderá ser feito ali. Sim, poderá, mas o resultado poderá ser aproximado, ou não. É fato que os alunos chegam ao ensino médio, sem o domínio conceitual mínimo do vocabulário próprio da História, que no geral, lhes parece estranho e muitas palavras causam risos nas turmas. É assim, por exemplo, com feudo, corvéia, talha, banalidades... Só pra ficar na Idade Média.

Um dos primeiros desafios de um professor de história, ao entrar em uma sala de aula do ensino básico público, é conseguir a atenção dos seus alunos. A dispersão da turma, por exemplo, pode acontecer em uma fração de segundo. Concentração e silêncio fazem parte de um busca constante. Munir-se de estratégias didáticas e pedagógicas é condição, para que a 
condução do trabalho de ensino e aprendizagem de história possa acontecer de forma minimamente possível. Alguns professores se irritam, gritam, se estressam, saem das salas de aula...outros, esperam calmamente, que sua presença seja notada pela turma. Aulas que começam a ser tecidas com fios de irritação, raramente rendem. Insisto que pouco se fala nisso.

Trazer a leitura e a escrita para as aulas de história representa a possibilidade de criação de outras formas de relação com o saber histórico escolar. Ao fazer uma leitura pública (Chatier, 1997), é possível identificar, por exemplo, traços sociais, lingüísticos, e de domínios acerca da linguagem conceitual da história ensinada, pois, a forma como um aluno lê uma palavra, pode indicar seu grau de familiaridade com ela, e isso ser um sinal para o professor. A língua é um instrumento emancipatório do humano, Ross (2016), assim, dar a palavra, escrita ou falada para o aluno, na aula de história pode representar a possibilidade de criar uma relação importante com o espaço humano, em que se produz o conhecimento.

Concordamos com Charlot (2001), que aprender implica, também, apropriar-se de uma forma de interiorizar uma prática, uma forma de se relacionar com o saber. É uma forma de se ver, e de ver os outros com os quais nos relacionamos. Se, em uma turma com 40 alunos, há num primeiro momento uma produção textual e dessa produção, a metade dos textos são lidos em classe, haverá uma imersão da turma em um tema da história, que, certamente será um processo composto por silêncios, audições, tempos diversos de leitura dos textos, nervosismos, risos, pausas, começos e recomeços...isso pode criar uma atmosfera de relação de significados, emancipações, aproximações com o saber história ensinado. Um dar a palavra. Um (re)criar espaços de socialização e de construção e fortalecimento da cidadania, condição básica para a democracia.

\section{REFERÊNCIAS}

ADORNO, Theodor. Educação e Emancipação. Rio de Janeiro: Paz e Terra, 2003

Dialética do Esclarecimento. Rio de Janeiro; Jorge Zahar Editor,1985.

BENTO, Luis Carlos. O saber histórico e o ensino de história: uma reflexão sobre as possibilidades do ensino escolar da história. UFG, 2015.

BATISTA, Djalma. Amazônia Cultura e Sociedade. Manaus: Valer, 2006. 
CHARTIER, Roger. A aventura do livro: do leitor ao navegador. São Paulo: Unesp, 1997.

CHARLOT, Bernard. Os jovens e o saber: Perspectivas mundiais. Curitiba: Armed, 2001.

CERTEAU, Michel de. A cultura no plural. São Paulo: Papirus, 2016.

OLIVEIRA, Myriam Cyntia Cesar. Diversidade socioambiental e dinâmicas da relação sociedade-natureza na área de fronteira agrária do sudeste do Pará. Tese, UFRS, 2007.

ROCHA, Helenice Aparecida Bastos. A escrita como condição para o ensino e a aprendizagem de história. São Paulo: Papirus, 2010.

RIBEIRO, Graci Tadeu Ferreira. Reflexões sobre o ensino de história e o saber histórico na sala de aula. Anais. III EDIPE, Encontro Estadual de didática e prática de ensino, Manaus, 2009.

ROSS, Paulo Ricardo. Contribuições ao conceito social da deficiência Humana. In.

Deficiência visual e inclusão escolar: Desfazendo rótulo. Belo Horizonte: CRV, 2016.

TEIXEIRA JÚNIOR, Tiese. Fazendo as pazes com a natureza? Curitiba: Prismas, 2017. 